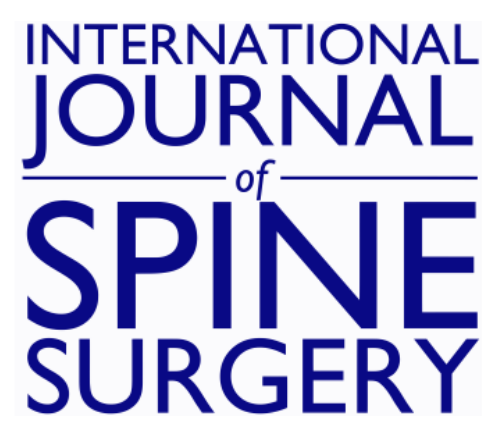

\title{
Segmental Contributions to Lumbar Lordosis: A Computed Tomography Study
}

\author{
JOSEPH F. BAKER and PETER A. ROBERTSON
}

Int J Spine Surg 2020, 14 (6) 949-955

doi: https://doi.org/10.14444/7144

http://ijssurgery.com/content/14/6/949

This information is current as of April 26, 2023.

Email Alerts Receive free email-alerts when new articles cite this article. Sign up at: http://ijssurgery.com/alerts 


\title{
Segmental Contributions to Lumbar Lordosis: A Computed Tomography Study
}

\author{
JOSEPH F. BAKER, MCH, FRCSI, ${ }^{1,2}$ PETER A. ROBERTSON, MD, FRACS ${ }^{3}$ \\ ${ }^{I}$ Department of Orthopaedic Surgery, Waikato Hospital, Hamilton, New Zealand, ${ }^{2}$ Department of Surgery, University of Auckland, Auckland, New Zealand, \\ ${ }^{3}$ Department of Orthopaedic Surgery, Auckland City Hospital, Auckland, New Zealand
}

\begin{abstract}
Background: The aim of this study was to determine the contribution of individual vertebral body lordosis to lumbar lordosis and establish the relationship of vertebral body lordosis to the pelvic incidence (PI).

Methods: One-hundred and two computed tomography (CT) scans on patients free of radiographic disease were measured for PI and segmental lordosis of both bone and disc from L1 to sacrum. Correlative analysis and analysis of variance (ANOVA) were used to identify contribution from bone and disc to lordosis.

Results: The mean total bony lordosis was $10.8^{\circ}\left(\mathrm{SD} 11.5^{\circ}\right)$, mean total disc lordosis was $36.3^{\circ}\left(\mathrm{SD} 9.9^{\circ}\right)$, and mean combined lordosis was $47.1^{\circ}$ (SD $10.0^{\circ}$ ). The mean PI of the entire cohort was $49.2^{\circ}$ (SD 9.3 $)$. One-way ANOVA demonstrated a significant difference between the PI strata in total bony lordosis values with a mean difference of $14.0^{\circ}$ between low and high PI cohorts $(P<.001)$ and also mid- and high PI cohorts of $9.9^{\circ}(P=.008)$. Overall, distal lordosis represented $80.8 \%$ of the total lordosis. In the proximal lumbar segments, the mean contribution from bone was $-4.0^{\circ}$ $\left(\mathrm{SD} 6.8^{\circ}\right)$ and the mean contribution from disc was $13.6^{\circ}\left(\mathrm{SD} 6.0^{\circ}\right)$. In the distal, the mean contribution from bone was $14.7^{\circ}\left(\mathrm{SD} 6.5^{\circ}\right)$ and from disc, $22.7^{\circ}\left(\mathrm{SD} 6.2^{\circ}\right)$.

Conclusions: The contribution to lordosis from the vertebral bodies is greater in the proximal lumbar spine with increasing PI. With low PI, the proximal vertebral bodies demonstrate reduced contribution to lordosis and in some instances are kyphotic. Future research efforts should place greater emphasis on providing segmental rather than just global analysis of alignment.

Clinical Relevance: Restoration of lumbar spine lordosis should take into account the variation in segmental lordosis contributions as it relates to PI.

Lumbar Spine

Keywords: lumbar lordosis, segmental lordosis, pelvic incidence
\end{abstract}

\section{INTRODUCTION}

Patient-specific sagittal alignment of the spine is well-established as a surgical goal in reconstructive procedures on the spinal column. Numerous studies have reported the clinical significance of imbalance and the importance of restoring balance during surgery with failure to do so compromising the patients' clinical outcome resulting in poorer healthrelated quality of life scores, increased pain, and higher rates of revision surgery. ${ }^{1-5}$

The pelvic incidence (PI), first described over 30 years ago, is the corner stone of surgical planning. ${ }^{6}$ The ideal individual lumbar lordosis (LL) can be predicted from the PI, a fixed anatomic value that does not change once an individual reaches skeletal maturity. When the PI and LL mismatch is greater than $10^{\circ}$ significant deterioration in health-related quality of life (HRQOL) scores are seen, the potential for adjacent segment disease increased and need for revision surgery is greater. $\mathrm{PI}=\mathrm{LL}$ has formed the basis for initial surgical planning of lordosis recreation. ${ }^{5,7,8}$ More recently, with analysis of large data sets, the ability to predict idealized LL for an individual has been enhanced with more precise calculations being offered. ${ }^{9,10}$ However, part of the complexity in planning sagittal realignment is the reliance on normative data from data sets using imaging taken with the subject standing. It is increasingly acknowledged that other functional positions including sitting and lying should be considered when considering what the ideal alignment is for an individual.

An important step in the evolution of surgical planning has been the understanding of segmental contributions throughout the lumbar spine and how these relate to the PI. Anwar et $\mathrm{al}^{11}$ demonstrated that a majority of LL arises from the caudad 2 (L4/5 
and L5/S1) motion segments but that the contribution from the more cephalad segments $(\mathrm{L} 1 / 2, \mathrm{~L} 2 / 3$, and L3/4) increased with increasing PI. ${ }^{11}$ Similarly, Pesenti et $\mathrm{al}^{12}$ detailed that the lower 2 motion segments contribute over $60 \%$ of LL but noted that PI only correlated with the LL in the proximal lumbar spine. The findings of Anwar et $\mathrm{al}^{11}$ and Pesenti et $\mathrm{al}^{12}$ underpin the development of the Global Alignment and Proportion Score, which indicated the need to ensure that recreation of LL is achieved in the correct region of the spine. $9,11,12$

Previous analysis of segmental contributions to LL have used plain radiographs using cohorts of patients attending a spinal deformity clinic and asymptomatic volunteers. Assessment using advanced imaging modalities, such as computed tomography (CT), offers advantages over plain radiography including optimum imaging of the mid sagittal plane of the vertebral body, and the ability to accurately identify transitional anatomy and pathologic processes. The aim of this study, utilizing CT imaging, was to define the contribution of the individual vertebral bodies and discs to LL, define the contribution to proximal and distal lordosis, and relate these contributions to the PI.

\section{METHODS}

Local ethical approval was obtained for this study (Health and Disability Ethics Committee; 18/ CEN/8).

CT images obtained for major trauma assessment were obtained from the hospital radiology server over a 1-year period, July 2017-August 2018. All scans were taken with the patient supine. Scans were reviewed to identify those that included imaging of the entire spinal column and pelvis.

In an attempt to minimize pathologic spines from analysis, scans were then excluded from analysis if there was any destructive pathology (trauma, tumor, infection) or previous surgery (spinal fusion, spinal instrumentation, hip arthroplasty) that precluded measurement of sacropelvic parameters or segmental spinal values. Scans were also excluded from analysis if there was evidence of degenerative spinal column disease including the presence of osteophyte, endplate sclerosis, or vacuum phenomena of the disc, and if there was antero- or retrolisthesis or evidence of spondylolysis. All scans were reviewed to determine the presence of 7 cervical, 12 thoracic, and 5 lumbar vertebrae and patients with abnormal numbering

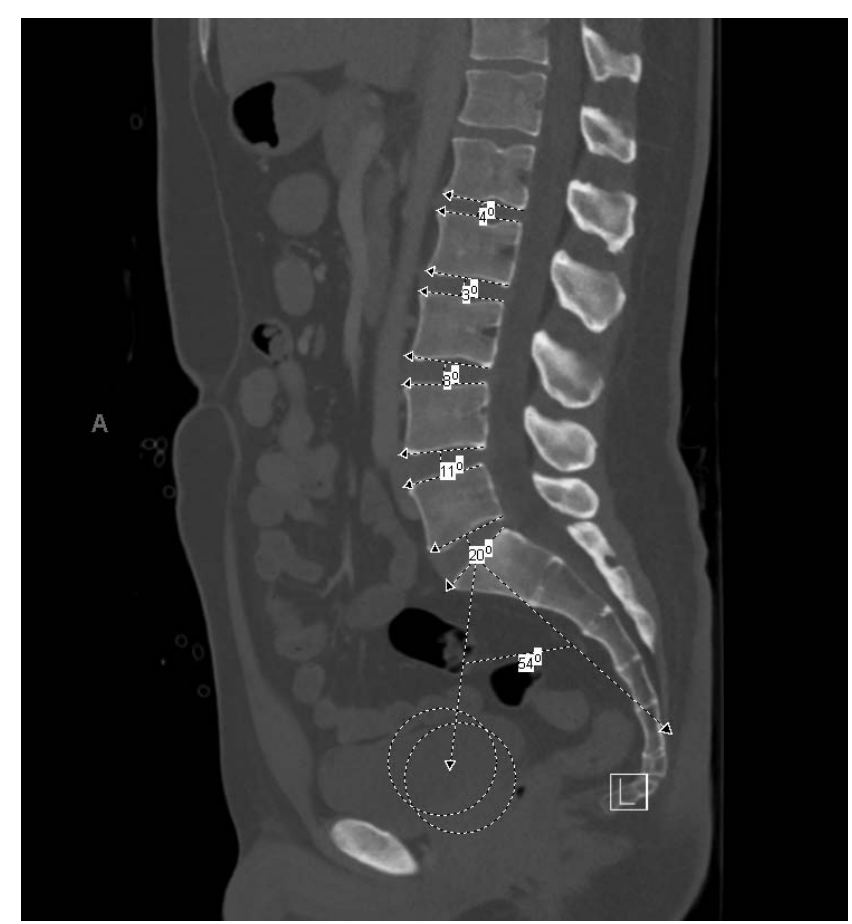

Figure 1. Technique for measuring the pelvic incidence $(\mathrm{PI})$ and segmental disc angles.

excluded. Finally, patients with Castellvi Type III and IV transitional lumbosacral vertebrae were excluded. ${ }^{13}$

Basic demographic data including age and gender were recorded. All images were analyzed on the IntelliSpace PACS 4.4 Enterprise (Koninklijke Phillips, NV). PI was measured as well described identifying the center of the femoral heads on the respective sagittal slices, then identifying the bicoxofemoral axis in the midsagittal plane (Figure 1). ${ }^{6}$ In the midsagittal plane, the endplates were identified of each vertebral body from L1 to L5 and the sacrum allowing measurement of the vertebral body and disc angles (Figures 1 and 2). A negative value indicated a kyphotic value whilst a positive value was lordotic.

Segmental values were considered in isolation but also as total vertebral body values, total disc values, and total combined. Lordosis was also assessed according to location, either proximal (measures from the superior endplate of L1 to the superior endplate of L4) or distal (all measures from the superior endplate of L4 to the endplate of S1).

The entire cohort was analyzed as a whole and then subgroup analysis performed based on stratification of the PI into low-, mid-, and high-value groups as has previously been done. ${ }^{12}$ 


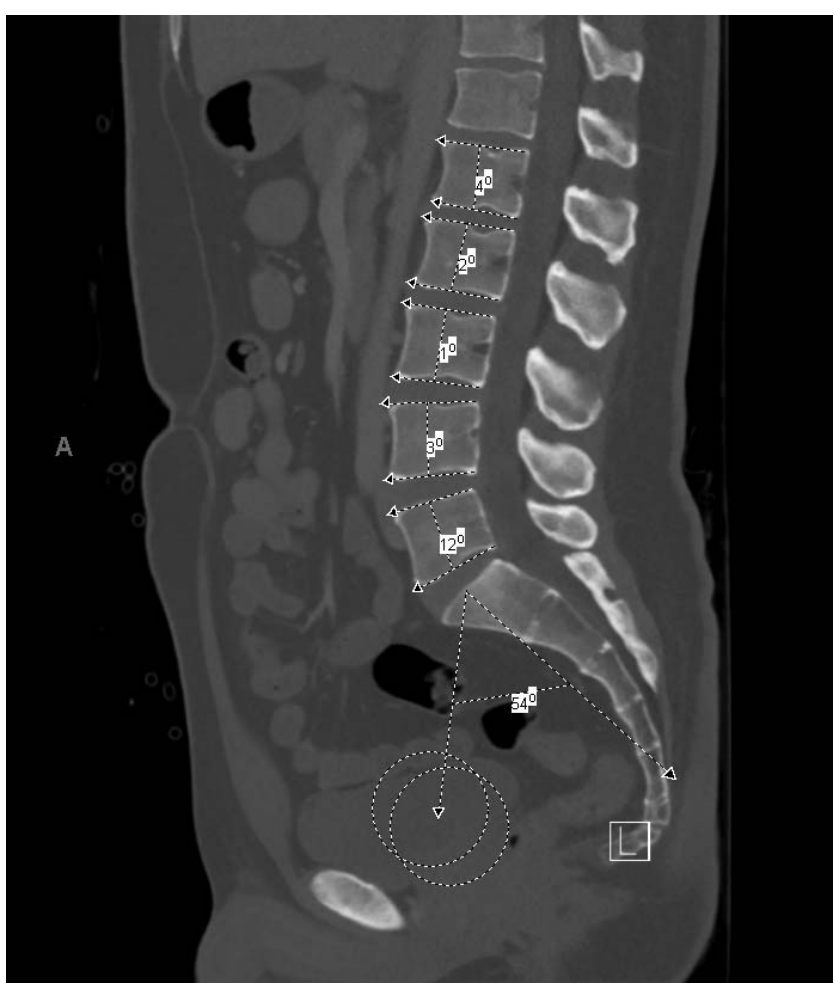

Figure 2. Technique for measuring the pelvic incidence $(\mathrm{PI})$ and segmental vertebral body angles.

\section{Statistics}

All data were recorded and stored on an Excel spreadsheet. Basic statistical results are reported as mean (and SD). As required, a 1-way analysis of variance (ANOVA) and Pearson correlation analysis was performed using the Jamovi statistics package. A posthoc Tukey test was used for intergroup comparison as required. For all tests, statistical significance was set at $P<.05$.

\section{RESULTS}

Scans of 102 patients were included in the analysis. The mean age of the cohort was 37.4 years (SD 14.4; range 17-68 years), with 67 males (66\%). The mean total bony lordosis was $10.8^{\circ}\left(11.5^{\circ}\right)$, mean total disc lordosis was $36.3^{\circ}\left(9.9^{\circ}\right)$, and mean combined lordosis was $47.1^{\circ}\left(10.0^{\circ}\right)$.

The mean PI of the entire cohort was $49.2^{\circ}\left(9.3^{\circ}\right)$. When the PI was stratified into low-, mid-, and high-value subgroups: 24 had a PI $\leq 45^{\circ}, 34$ a PI $46^{\circ}-60^{\circ}$, and 9 a PI $>60^{\circ}$. There was no significant difference in the mean age between PI strata $(P=$ .267) nor any significant correlation between age and PI $(r=.069 ; P=.488)$.

\section{Combined Lordosis}

The mean total lordosis for low-, mid-, and high PI strata was $40.4^{\circ}\left(8.5^{\circ}\right), 50.0^{\circ}\left(9.2^{\circ}\right)$, and $54.3^{\circ}$ $\left(5.4^{\circ}\right)$, respectively. One-way ANOVA revealed significant differences between low and mid-PI strata $\left(9.6^{\circ}, P<.001\right)$, between low and high PI strata $\left(13.9^{\circ}, P<.001\right)$ but not between mid- and high PI strata $\left(4.3^{\circ}, P=.223\right)$.

\section{Contribution From Vertebral Bodies}

Table 1 shows the results from the individual bony measures across the entire cohort but also by stratification of PI. One-way ANOVA demonstrated a significant difference between the PI strata in total bony lordosis values with a mean difference of $14.0^{\circ}$ between low and high PI cohorts $(P<.001)$ and also mid- and high PI cohorts of $9.9^{\circ}(P=.008)$. There was no significant difference between low and mid-PI $\left(4.1^{\circ} ; P=.184\right)$.

\section{Contribution From Discs}

Table 2 shows the results from the individual disc measurements across the entire cohort and by stratification of PI. One-way ANOVA showed a significant difference in the total discal lordosis values with a mean difference of $5.5^{\circ}$ between low and mid-PI cohorts $(P=.023)$. There was no significant difference detected between low and high PI cohorts $\left(0.04^{\circ} ; P=1.0\right)$ and mid- and high PI cohorts $\left(5.6^{\circ} ; P=.134\right)$.

Table 1. Mean (and SD) values are provided for the vertebral body lordosis at each level for the entire cohort and by stratification of pelvic incidence into low, mid, and high groups. $P$ values provided are from the 1-way analysis of variance comparing values according to the stratification.

\begin{tabular}{|c|c|c|c|c|c|c|}
\hline & $\mathbf{L 1}$ & $\mathbf{L 2}$ & $\mathbf{L 3}$ & L4 & $\mathbf{L 5}$ & TBL \\
\hline Complete & $-4.5^{\circ}\left(3.3^{\circ}\right)$ & $-1.3^{\circ}\left(2.8^{\circ}\right)$ & $1.8^{\circ}\left(2.5^{\circ}\right)$ & $4.5^{\circ}\left(3.3^{\circ}\right)$ & $10.2^{\circ}\left(4.4^{\circ}\right)$ & $10.7^{\circ}\left(11.5^{\circ}\right)$ \\
\hline Low PI & $-5.4^{\circ}\left(3.3^{\circ}\right)$ & $-2^{\circ}\left(2.7^{\circ}\right)$ & $0.9^{\circ}\left(2.5^{\circ}\right)$ & $3.7^{\circ}\left(3.4^{\circ}\right)$ & $9.6^{\circ}\left(3.7^{\circ}\right)$ & $6.8^{\circ}\left(10.6^{\circ}\right)$ \\
\hline Mid PI & $-4.3^{\circ}\left(3.5^{\circ}\right)$ & $-1.2^{\circ}\left(2.9^{\circ}\right)$ & $1.8^{\circ}\left(2.1^{\circ}\right)$ & $4.5^{\circ}\left(3.1^{\circ}\right)$ & $10.1^{\circ}\left(4.8^{\circ}\right)$ & $10.9^{\circ}\left(11.1^{\circ}\right)$ \\
\hline High PI & $-2.9^{\circ}\left(2.4^{\circ}\right)$ & $0.3^{\circ}\left(1.9^{\circ}\right)$ & $4.3^{\circ}\left(2.8^{\circ}\right)$ & $6.6^{\circ}\left(3.1^{\circ}\right)$ & $12.5^{\circ}\left(4.1^{\circ}\right)$ & $20.8^{\circ}\left(8.8^{\circ}\right)$ \\
\hline$P$ value & .017 & .006 & .002 & .023 & .078 & $<.001$ \\
\hline
\end{tabular}


Table 2. Mean (and SD) values are provided for the disc lordosis at each level for the entire cohort and by stratification of pelvic incidence into low, mid, and high groups. $P$ values provided are from the 1-way analysis of variance comparing values according to the stratification.

\begin{tabular}{lcccccc}
\hline & $\mathbf{L 1 / 2}$ & $\mathbf{L 2 / 3}$ & $\mathbf{L 3 / 4}$ & $\mathbf{L 4 / 5}$ & $\mathbf{L 5 / S 1}$ & TDL \\
\hline Complete & $3.6^{\circ}\left(2.5^{\circ}\right)$ & $4.4^{\circ}\left(2.5^{\circ}\right)$ & $5.5^{\circ}\left(2.6^{\circ}\right)$ & $8.5^{\circ}\left(2.7^{\circ}\right)$ & $14.2^{\circ}\left(4.8^{\circ}\right)$ & $36.3^{\circ}\left(9.9^{\circ}\right)$ \\
Low PI & $3.7^{\circ}\left(2.3^{\circ}\right)$ & $4.1^{\circ}\left(2.0^{\circ}\right)$ & $4.8^{\circ}\left(2.5^{\circ}\right)$ & $7.4^{\circ}\left(2.6^{\circ}\right)$ & $13.4^{\circ}\left(4.8^{\circ}\right)$ & $33.5^{\circ}\left(9.0^{\circ}\right)$ \\
Mid PI & $3.8^{\circ}\left(2.7^{\circ}\right)$ & $4.8^{\circ}\left(2.8^{\circ}\right)$ & $6.1^{\circ}\left(2.6^{\circ}\right)$ & $9.3^{\circ}\left(2.6^{\circ}\right)$ & $15.1^{\circ}\left(5.0^{\circ}\right)$ & $39.1^{\circ}\left(10.1^{\circ}\right)$ \\
High PI & $2.9^{\circ}\left(2.5^{\circ}\right)$ & $3.7^{\circ}\left(2.2^{\circ}\right)$ & $5.1^{\circ}\left(2.4^{\circ}\right)$ & $8.4^{\circ}\left(2.8^{\circ}\right)$ & $13.4^{\circ}\left(4.3^{\circ}\right)$ & $33.5^{\circ}\left(8.9^{\circ}\right)$ \\
$P$ value & .443 & .230 & .086 & .011 & .219 & .022 \\
\hline
\end{tabular}

\section{Proximal and Distal Contributions}

When the entire cohort was analyzed, the mean proximal lordosis was $9.6^{\circ}\left(6.4^{\circ}\right)$, and the mean distal lordosis was $37.5^{\circ}\left(7.1^{\circ}\right)$. Overall, distal lordosis represented $80.8 \%$ of the total lordosis. In the proximal lumbar segments, the mean contribution from bone was $-4.0^{\circ}\left(6.8^{\circ}\right)$, and the mean contribution from disc was $13.6^{\circ}\left(6.0^{\circ}\right)$. In the distal, the mean contribution from bone was $14.7^{\circ}\left(6.5^{\circ}\right)$ and from disc, $22.7^{\circ}\left(6.2^{\circ}\right)$.

Considering the segmental contribution to lordosis from bone and disc in proximal and distal segments of the lumbar spine (Table 3), 1-way ANOVA showed significant differences in proximal bony lordosis between low and high PI strata $(P<$ $.001)$ and mid- and high PI strata $(P=.014)$ but not between low and mid-PI $(P=.127)$. In the proximal segments, 1-way ANOVA did not reveal any significant difference in the segmental disc measurements between strata. In the distal segments, there was a significant difference between the low and mid-PI strata $(P=.022)$ but not among the others.

Pearson correlation demonstrated the relationship between proximal and distal lumbar bone and disc contributions to lordosis (Table 4). Significant correlation was seen between the PI and lordosis measurements from bone but not disc. Age was also tested with a weak positive correlation evident with lordosis from proximal $(r=.343 ; P<.001)$ and distal disc measures $(r=.214 ; P=.031)$ but not with

Table 3. Mean (and SD) values are provided for the vertebral body and disc lordosis in proximal and distal segments of the lumbar spine for the entire cohort and by stratification of pelvic incidence into low, mid, and high groups. $P$ values provided are from the 1-way analysis of variance comparing values according to the stratification.

\begin{tabular}{lcccc}
\hline & L1-3 Bone & L4-5 Bone & L1/2/3/4 Disc & L4/5/S1 Disc \\
\hline Complete, $^{\circ}$ & $-4.0(6.8)$ & $14.7(6.5)$ & $13.6(6.0)$ & $22.7(6.2)$ \\
Low PI, $^{\circ}$ & $-6.3(6.2)$ & $13.2(5.9)$ & $12.7(5.2)$ & $20.8(5.9)$ \\
Mid PI, $^{\circ}$ & $-3.7(6.7)$ & $14.6(6.7)$ & $14.7(6.2)$ & $24.4(6.3)$ \\
High PI, $^{\circ}$ & $1.7(5.1)$ & $19.1(5.9)$ & $11.6(6.5)$ & $21.9(5.3)$ \\
$P$ value & $<.001$ & .013 & .159 & .034 \\
\hline
\end{tabular}

proximal $(r=.134, P=.179)$ nor distal bone measures $(r=.125 ; P=.209)$.

\section{DISCUSSION}

The aim of this study, using a series of CT images for analysis, was to define the contributions of the individual vertebral bodies and discs to $\mathrm{LL}$ in the supine position using a series of $\mathrm{CT}$ images for analysis. Although it was shown that the contribution to lordosis from the vertebral bodies increased from proximal to distal, we determined that the mean lordosis of the proximal vertebral bodies increased with increasing PI. The contribution to overall lordosis from the L1-3 vertebral bodies correlated with PI slightly more strongly than did the contribution from the L4-5 bodies.

It is clear, in conjunction with earlier findings by Anwar et $\mathrm{al}^{11}$ and Pesenti et al, ${ }^{12}$ that the higher the PI is, the more the proximal segments contribute to LL. Anwar et $\mathrm{al}^{11}$ noted that the L1 and L2 vertebral bodies were actually kyphotic with mean angles of $-0.56^{\circ}$ and $-0.35^{\circ}$, respectively. The results here were more marked with values of $-4.5^{\circ}$ and $-1.3^{\circ}$ - this difference may reflect the use of an alternate imaging modality for assessment. Pesenti et $\mathrm{al}^{12}$ do not provide separate analysis of vertebral body and disc angles but report the segmental lordosis reflecting the combined contribution of bone and disc at each level. In contrast to their finding that PI did not correlate with distal lumbar segmental lordosis, this current study demonstrated that PI correlated with the vertebral body lordosis values in both proximal and distal regions of the lumbar spine. ${ }^{12}$ This is a further key finding for surgical planning and suggests that the variation in proportional lordosis between the proximal and distal regions of the lumbar spine, at least in the standing position, is primarily influenced by the lordotic change in the disc space. Indeed, it is well described how lordosis changes between positions 
Table 4. Results from the Pearson correlation matrix demonstrating relationship of pelvic incidence with the proximal and distal lumbar bone and disc lordosis measures.

\begin{tabular}{|c|c|c|c|c|}
\hline & L1-3 Bone & L4-5 Bone & L1/2/3/4 Disc & L4/5/S1 Disc \\
\hline Pearson $r$ & .412 & .328 & .017 & .126 \\
\hline $\begin{array}{l}95 \% \text { confidence } \\
\text { interval }\end{array}$ & 0.236 to 0.561 & 0.142 to 0.491 & -0.179 to 0.210 & -0.070 to 0.313 \\
\hline$P$ value & $<.001$ & $<.001$ & .869 & .206 \\
\hline
\end{tabular}

and one can anticipate that the disc angle would vary between standing and supine positions. ${ }^{14}$

In a study comparing the contribution to lordosis in humans and macaques, Been et $\mathrm{al}^{15}$ report kyphotic wedging in the proximal 2 vertebral bodies with mean values of $-4^{\circ}$ and $-1^{\circ}$ at L1 and L2, respectively. Similarly, $\mathrm{Chen}^{16}$ described kyphotic angulation at these levels in a population of Chinese males with mean values, in a neutral standing position, of $-5.8^{\circ}$ and $-4.4^{\circ}$. Neither study provides an analysis of the vertebral body contribution to lordosis with consideration of the PI and how the measures may be related. Although Vialle et $\mathrm{al}^{17}$ analyzed the segmental contributions to lordosis from the lower thoracic spine to the sacrum, the measures do not isolate the vertebral body contributions.

Consideration of the contribution to lordosis by the vertebral bodies and discs as separate entities is important. The failure of earlier work to describe the contributions of both vertebral body and disc is a key omission as knowing the separate contributions from both vertebral body and disc is important to allow an understanding of the ideal, or target, disc lordosis that should be restored at surgery. ${ }^{12}$ Using interbody devices to correct segmental loss of alignment, particularly over multiple levels, could lead to over- or undercorrection if one is not aware of the kyphotic nature of the adjacent vertebral body. ${ }^{18,19}$ This underpins the need to achieve proportional spread of lordosis highlighted by increased failure when lordosis recreation is not proportional. ${ }^{8,9}$ Future work analyzing segmental contribution to global LL should consist of separate vertebral body and disc space measurements.

Limitations of this study include the use of imaging taken in a single position. Ideally, parameters would be measured in each of lying, sitting, and standing positions for the same individuals, but exposure to such radiation would be unethical for the purposes of obtaining normative data. However,

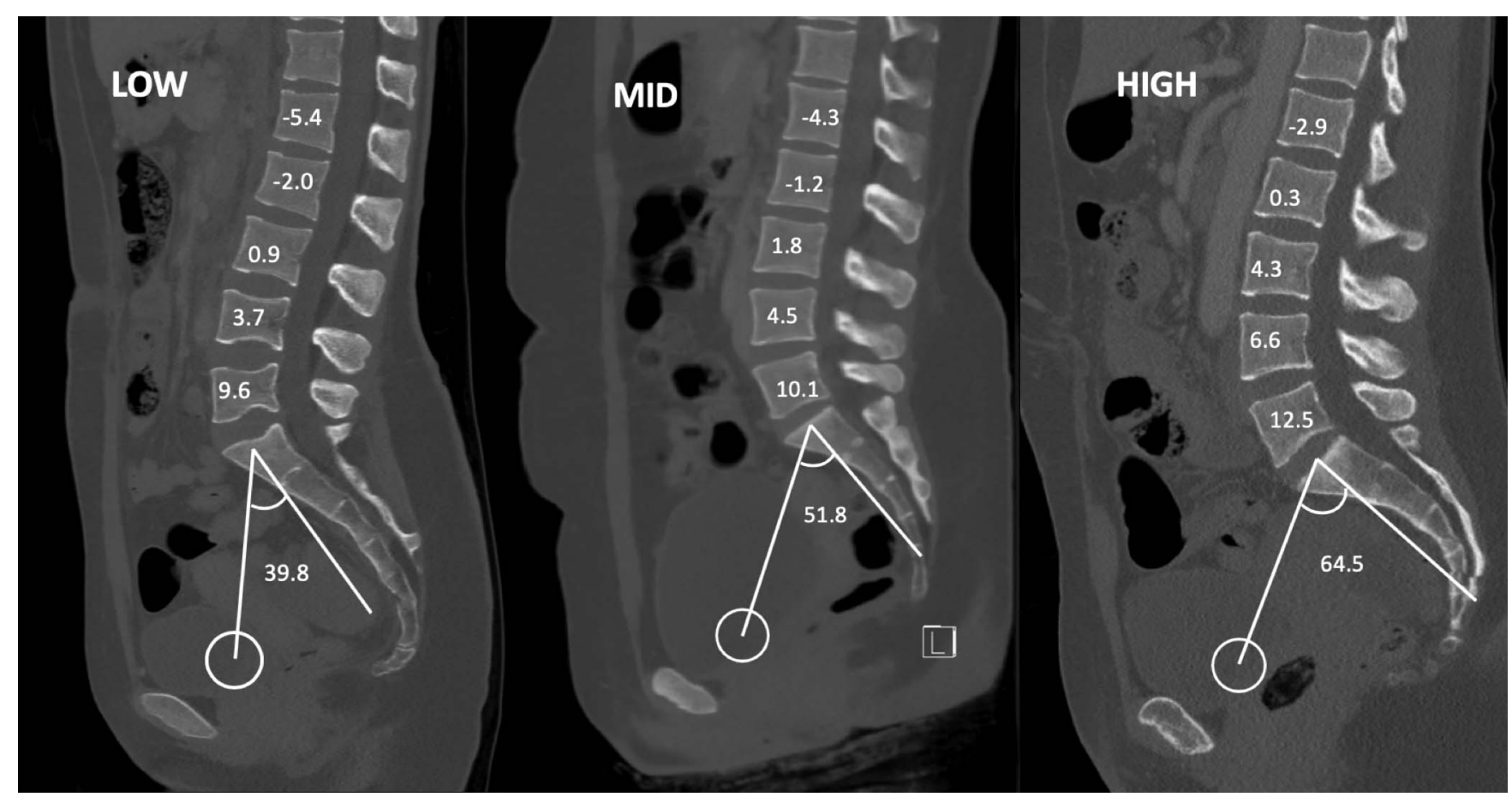

Figure 3. Mean vertebral body and pelvic incidence (PI) values for the low, mid, and high PI cohorts. 
it is equally important to consider 3 functional alignments of the spine - erect, supine, and sitting postures - and this current study adds to the growing body of literature that examines the segmental contributions to global LL. Consideration of spinal alignment in each posture will likely be critical as understanding of optimum lordotic recreation evolves. To date, much research has focused on alignment of the spine in the erect position and attempts to recreate alignment based on this normative data are still met with considerably high failure rates.

We attempted to minimize inclusion of pathologic spines based on the CT appearances - although this is not the ideal modality to assess degenerative disease, this is balanced against the ease of analysis using CT and also access to a large volume of whole spine imaging, which has other benefits including accurately determining vertebral body counts and detecting the presence of transitional anatomy. Similarly, we did not contact patients to ascertain the presence or absence of symptoms attributable to the spinal column, although we did not think the vertebral body measures would be significantly influenced by this given the exclusion criteria applied.

\section{CONCLUSION}

In summary, based on an analysis of CT scans in patients free of radiographic disease, it is evident that the vertebral body contributions to overall supine lordosis proportionally increase from proximal to distal, but the proximal contribution increases with increasing PI. Surgeons can take into account these findings during planning of patientspecific recreation of spinal alignment. Future efforts should consider reporting the contribution of the vertebral body and disc separately in addition to the segmental lordosis.

\section{REFERENCES}

1. Glassman SD, Berven S, Bridwell K, Horton W, Dimar JR. Correlation of radiographic parameters and clinical symptoms in adult scoliosis. Spine (Phila Pa 1976). 2005;30(6):682-688.

2. Rothenfluh DA, Mueller DA, Rothenfluh E, Min K. Pelvic incidence-lumbar lordosis mismatch predisposes to adjacent segment disease after lumbar spinal fusion. Eur Spine J. 2015;24(6):1251-1258.

3. Aoki Y, Nakajima A, Takahashi $\mathrm{H}$, et al. Influence of pelvic incidence-lumbar lordosis mismatch on surgical outcomes of short-segment transforaminal lumbar interbody fusion. BMC Musculoskelet Disord. 2015;16:213. doi:10.1186/ s12891-015-0676-1

4. Kyrola K, Repo J, Mecklin JP, Ylinen J, Kautiainen H, Hakkinen A. Spinopelvic changes based on the simplified SRSSchwab Adult Spinal Deformity Classification: relationships with disability and health-related quality of life in adult patients with prolonged degenerative spinal disorders. Spine (Phila Pa 1976). 2018;43(7):497-502.

5. Smith JS, Klineberg E, Schwab F, et al. Change in classification grade by the SRS-Schwab Adult Spinal Deformity Classification predicts impact on health-related quality of life measures: prospective analysis of operative and nonoperative treatment. Spine (Phila Pa 1976). 2013;38(19):1663-1671.

6. Legaye J, Duval-Beaupere G, Hecquet J, Marty C. Pelvic incidence: a fundamental pelvic parameter for three-dimensional regulation of spinal sagittal curves. Eur Spine J. 1998;7(2):99103.

7. Tempel ZJ, Gandhoke GS, Bolinger BD, et al. The influence of pelvic incidence and lumbar lordosis mismatch on development of symptomatic adjacent level disease following single-level transforaminal lumbar interbody fusion. Neurosurgery 2017;80(6):880-886.

8. Yilgor C, Sogunmez N, Yavuz Y, et al. Relative lumbar lordosis and lordosis distribution index: individualized pelvic incidence-based proportional parameters that quantify lumbar lordosis more precisely than the concept of pelvic incidence minus lumbar lordosis. Neurosurg Focus. 2017;43(6):E5.

9. Yilgor C, Sogunmez N, Boissiere L, et al. Global Alignment and Proportion (GAP) Score: development and validation of a new method of analyzing spinopelvic alignment to predict mechanical complications after adult spinal deformity surgery. J Bone Joint Surg Am. 2017;99(19):1661-1672.

10. Xu L, Qin X, Zhang W, et al. Estimation of the ideal lumbar lordosis to be restored from spinal fusion surgery: a predictive formula for Chinese population. Spine (Phila $\mathrm{Pa}$ 1976). 2015;40(13):1001-1005.

11. Anwar HA, Butler JS, Yarashi T, Rajakulendran K, Molloy S. Segmental Pelvic Correlation (SPeC): a novel approach to understanding sagittal plane spinal alignment. Spine J 2015;15(12):2518-2523.

12. Pesenti S, Lafage R, Stein D, et al. The amount of proximal lumbar lordosis is related to pelvic incidence. Clin Orthop Relat Res. 2018;476(8):1603-1611.

13. Castellvi AE, Goldstein LA, Chan DP. Lumbosacral transitional vertebrae and their relationship with lumbar extradural defects. Spine (Phila Pa 1976). 1984;9(5):493-495.

14. Yasuda T, Hasegawa T, Yamato $Y$, et al. Effect of position on lumbar lordosis in patients with adult spinal deformity. J Neurosurg Spine. 2018;29(5):530-534.

15. Been E, Barash A, Marom A, Kramer PA. Vertebral bodies or discs: which contributes more to human-like lumbar lordosis? Clin Orthop Relat Res. 2010;468(7):1822-1829.

16. Chen YL. Geometric measurements of the lumbar spine in Chinese men during trunk flexion. Spine (Phila Pa 1976). 1999;24(7):666-669.

17. Vialle R, Levassor N, Rillardon L, Templier A, Skalli W, Guigui P. Radiographic analysis of the sagittal alignment and balance of the spine in asymptomatic subjects. J Bone Joint Surg Am. 2005;87(2):260-267.

18. Robertson PA, Armstrong WA, Woods DL, Rawlinson JJ. Lordosis re-creation in TLIF and PLIF: a cadaveric study of 
the influence of surgical bone resection and cage angle. Spine (Phila Pa 1976). 2018;43(22):E1350-E1357.

19. Molloy S, Butler JS, Benton A, Malhotra K, Selvadurai $\mathrm{S}$, Agu O. A new extensile anterolateral retroperitoneal approach for lumbar interbody fusion from L1 to S1: a prospective series with clinical outcomes. Spine $J$. 2016;16(6):786-791.

Disclosures and COI: The authors received no funding for this study and report no conflicts of interest.

Corresponding Author: Joseph Baker, MCh,
FRCSI, Department of Orthopaedic Surgery, Waikato Hospital, Pembroke St, Hamilton, New Zealand. Phone: +64-7-8398899. Email: joseph.f. baker@gmail.com; joe.baker@auckland.ac.nz.

Published 22 January 2021

This manuscript is generously published free of charge by ISASS, the International Society for the Advancement of Spine Surgery. Copyright ( 2020 ISASS. To see more or order reprints or permissions, see http://ijssurgery.com. 